\title{
Research on the Construction of Age-Friendly
} Community Based on Fuzzy Comprehensive

\section{Evaluation Model: Evidence from Community in Hefei of China}

\author{
Lin $\operatorname{Pan}^{1,2}$ \\ Jian $\operatorname{Sun}^{3}$ \\ Rongting Zhou ${ }^{2}$ \\ 'Department of Basic Education, Party \\ School of Anhui Provincial Committee \\ (Anhui Academy of Governance), Hefei, \\ 230022, People's Republic of China; \\ ${ }^{2}$ Department of Sci-Tech Communication \\ and Policy, University of Science and \\ Technology of China, Hefei, 230026, \\ People's Republic of China; ${ }^{3}$ School of \\ International and Public Affairs, Shanghai \\ Jiao Tong University, Shanghai, 200030, \\ People's Republic of China
}

Background and Aim: The construction of an age-friendly community is beneficial to meeting the needs of the elderly and coping with ageing. It is significant to evaluate the quality of age-friendly communities through scientific methods. The study aims to evaluate the livability of communities among the elderly in China.

Methods: The data used in this study were sourced from the community of Hefei in China, including 1426 participants aged 60 and above. Taking community in Hefei of China as an example, the analytic hierarchy process fuzzy comprehensive evaluation model was used to evaluate the community. Furthermore, this paper constructs an evaluation index system for the livable elderly community and evaluates the comprehensive community system with the fuzzy comprehensive evaluation method.

Results: This study constructs the evaluation index system of an age-friendly community that includes five first-level evaluation indexes and 33 second-level evaluation indexes. The first-level indexe satisfaction from high to low are community safety, community comfort, community health and convenience, and community service. Among them, flat roads (more than $74.3 \%$ ), greening (more than $78 \%$ ), quietness (more than $76.8 \%$ ), health situation (more than $65 \%$ ), and public transport facilities (more than $66 \%$ ) were relatively satisfactory. However, in terms of community service, the overall satisfaction of the elderly is not high.

Conclusion: This study revealed that the level of the age-friendly community in Hefei of China is relatively high. The community safety score is the highest, comfort is relatively high, followed by community health and convenience. The score of community service was low. Moreover, the results indicated that improving the quality of service has become the key to improving the satisfaction of the elderly in the community.

Keywords: age-friendly community, satisfaction, index system, fuzzy comprehensive evaluation method, China

\section{Introduction}

At present, population aging has gradually become a daunting challenge for governments. Managers in different countries and regions generally recognize that it is essential to create an elderly livable community and continuously improve the quality and efficiency of elderly services to meet the needs of the elderly. As an indicator that directly reflects the quality of life and well-being
School of International and Public Affairs, Shanghai Jiao Tong University, 1954

Huashan Road, Xuhui District, Shanghai, 200030, People's Republic of China

Tel +86-188-1693-0536

Email sjjjw6@sjtu.edu.cn 
of the elderly, it is of great significance to improve the weak link of the existing community and enhance the life satisfaction of the elderly.

In 1961, World Health Organization (WHO) proposed that the basic concept of matching human settlements reflects people's living environment, including safety, health, convenience and comfort. This reflects the basic principles of building livable communities. To cope with the aging population, the WHO published the global guidelines for the construction of elderly friendly cities in 2007, which identified three aspects of the elderly friendly cities: urban physical environment, social and cultural environment, health, social environment and services. Gradually, more than 500 elderly friendly cities and livable community networks have been gradually established in 37 countries around the world, ${ }^{1}$ which has comprehensively promoted the construction of livable communities worldwide.

According to the United Nations standards, China has entered an aging society since 1999. China's aging presents many new characteristics, such as a large scale, a fast growth rate, and a heavy response task. With the deepening of aging, the community environment is also aging, and the city faces double aging. In 2016, the national office for the aged and other 25 departments jointly issued the guiding opinions on promoting the construction of a livable environment for the elderly, which aims to improve the quality of life and happiness of the elderly by building a suitable living environment, travel environment, health support environment, life service environment and social and cultural environment for the elderly. In 2017, the State Council issued relevant documents to improve the evaluation standard system of livable environment for the elderly. It carried out the demonstration action of age-friendly community. The Fifth Plenary Session of the 19th Communist Party of China Central Committee further proposed to implement a national strategy to respond to the aging of the population actively, and accelerate the construction of an elderly care service system with the coordination of home-based community institutions and the combination of medical care and health care. The actions of issuing policy documents and participating in the construction of livable communities by these departments mentioned above indicate that, strengthening the construction of a livable environment for the elderly at the community level is of great value for improving the quality of the living environment, improving the environment for the aged in home communities, and promoting the construction of a healthy green city.

With the rapid development of an age-friendly community, domestic and foreign academic circles have launched extensive discussions on the elderly livable community. ${ }^{2}$ Some scholars have different terms for livable community, such as elderly friendly community and lifelong community. Still, the core meaning refers to the excellent living environment created for the elderly. The WHO defines it as a community that improves the quality of life of the elderly and achieves active aging through the provision of health care, social participation and safety services. Foreign scholars' researches on livable communities tend to improve care, enrich activities and active aging. Many scholars believe that life satisfaction is one of the most important indicators of well-being. Alley et al thought that the key points of building an elderly friendly community are housing, health, safety, transportation, etc. ${ }^{3}$ Brownson et al proposed the impact variables of community built environment from the perspective of physical activity, mainly defined from four aspects of land use, transportation, aesthetics and safety. ${ }^{4}$ The ecological model of aging proposed by Lawton involves the degree of adaptation between people and their living environment. ${ }^{5,6}$ The goal of livable community construction is to help the elderly continue to live in the community and home. ${ }^{7,8}$ Greenfield et al argued that under the logic of stakeholder cooperation, the elderly friendly community could meet the diversified health needs of the elderly through the construction of the material environment and social environment. ${ }^{9}$

Chinese scholars emphasized the construction and evaluation of livable communities for the elderly. Li and Yang have constructed the evaluation index system of livable communities for the elderly. They believed that the elderly livable communities should be safe, healthy, convenient, comfortable, and have perfect service and emotional belonging. ${ }^{10} \mathrm{Yu}$ proposed that the construction space of a livable community environment for the elderly involves the outdoor setting of the community, community homebased elderly care service facilities and home-based aging measures. ${ }^{11} \mathrm{Li}$ et al believed that the livable environment for the elderly includes urban and rural environments, community environments and family environments suitable for the elderly. ${ }^{12}$ Zhou put forward that it is suitable for the living environment of all ages including the elderly, such as challenging environment (space and facilities), and quiet environment (society and culture). ${ }^{13} \mathrm{Wu}$ et al also 
believed that it refers to people of all ages, including the elderly, and it is the sum of living and living space. From the perspective of the physical space category. ${ }^{14}$ Zhang divided the livable environment for the elderly into the living environment, community environment, residential community environment, and social environment. ${ }^{15} \mathrm{Niu}$ et al have established a comprehensive evaluation model for the effect of energy-saving renovation of existing buildings based on the analytic hierarchy process (AHP) and cloud model. ${ }^{16}$ Zhang et al focused on evaluation on neighborhood satisfaction by fuzzy method and selected three neighborhoods with relatively high aging rate in Beijing as the case study. ${ }^{17} \mathrm{Li}$ et al employed the Fuzzy Comprehensive Evaluation to explore the effect of the system in long-term care of the elderly. ${ }^{18}$ Based on the characteristics of the old residential district and the particularity of renewal for the old residential district, Zhang et al divided the evaluation system of renewal for old residential district into three indexes, using AHM to determine weighting and evaluate vaguely. ${ }^{19}$ Other scholars have conducted fruitful research from the perspectives of livable system construction, green evaluation, and aging.

In terms of evaluation methods, principal factor analysis or analytic hierarchy process is usually adopted. These methods have single element evaluation and element summation score. The fuzzy comprehensive evaluation method combines qualitative and quantitative accurate and imprecise reasoning, and highlights the weights set by the person to be adjusted, which effectively alleviates this inconsistency. The research object of this article is the satisfaction of the elderly in the community, which is suitable for fuzzy evaluation method. Combining fuzzy evaluation method with AHP is a relatively common research combination, which can further enhance the scientific nature of fuzzy evaluation method.

To sum up, academic circles have carried out exploration and research on livable communities for the elderly. These scholars have not yet formed a unified standard for the evaluation of livable communities for the elderly. However, they all emphasized the necessity of infrastructure and service support environment, and the matching of people and living environment. However, the current research results also have apparent deficiencies. On the one hand, the existing research has not carried out systematic theoretical research and index system construction from the needs and satisfaction of the elderly. On the other hand, many references to the content of the index system of architecture are highly professional, without considering the characteristics and limitations of the integration of the elderly and the community living environment.

In this paper, with the needs and satisfaction of the elderly combined, the researcher can carry out quantitative research and scientific evaluation of multi-dimensional, multi-level and multi-body to guide and supervise the evaluation and improve the weak links in the construction of livable communities for the elderly. In this paper, based on AHP, the improved fuzzy comprehensive evaluation method was used to eliminate the subjectivity in the index weighting and expert scoring data processing. A comprehensive evaluation model for the elderly livable community was constructed. Taking community in Hefei of China as an example, this paper quantitatively analyzed the construction status of community livability, combined the weight of the first level index and the second level index obtained by the AHP with the expert scoring data, and gave the evaluation grade of each level index and the operation status of the whole system with the fuzzy comprehensive evaluation method. Based on the quantitative evaluation results, this paper analyzed the shortcomings of the current construction of the age-friendly community and gave targeted suggestions.

\section{Construction of Fuzzy Comprehensive Evaluation Model of the Age-Friendly Community}

The fuzzy comprehensive evaluation method can address the uncertainty and difficulty of quantifying problems. ${ }^{20}$ The comprehensive fuzzy evaluation method has the characteristics of a robust system and strict logic, which can provide a practical and intuitive decision-making basis for decision- makers. Therefore, based on the fuzzy comprehensive evaluation method, this paper evaluated the livable elderly community in Hefei, which can genuinely and scientifically reflect the actual situation of community construction.

This paper is based on the actual situation of economic development and community construction in Hefei of China, the theory of human settlements and the guidance of academic circles at home and abroad, as well as the index content of the construction of age-friendly community defined by who and relevant departments in China. In addition, the research context of livable cities in China and the reality of urban communities, combined with the needs and satisfaction of the elderly community life and the 
physiological and psychological characteristics of the elderly group, this paper divided the construction indicators of livable elderly communities into five dimensions: community safety, community health, community convenience, community comfort, and community service. To reflect whether the community takes the elderly as the object and provides various kinds of community services, the community service was added as a separate state indicator layer. The article focused on the key points and highlights livability based on ensuring a comprehensive evaluation. In the process of index setting, the principle of simplicity and accuracy, the reliability of survey data sources and the convenience of access were followed. At the same time, scoring method was used in the quantitative part, and 20 experts in the field were selected, including professors from University of Science and Technology of China, Anhui University and Hefei University of Technology, as well as staffs from the civil affairs department and the community. The expert opinions and satisfactory suggestions have been obtained in multiple feedback.

\section{Evaluation Index System of the Age-Friendly Community}

The age-friendly community is the coordinated development of the relevant influencing factors of the whole livable community in the existing living environment of the elderly, and this effectively resolves the contradiction between the growing needs of the elderly for a better life and the unbalanced inadequate development of the elderly career. At present, the comprehensive evaluation index system of the age-friendly community consists of 5 representative first-class indicators and 33 second-class indicators.

\section{Community Safety $\left(\mathrm{U}_{\mathrm{Ii}}\right)$}

Community is the basic unit of society, and community security is the cornerstone of social stability. Community safety refers to minimizing the probability of safety accident risk in the community. Even if there is an accident, the injury and loss can be controlled to a mild degree. Fourthly, it is essential to add convenient service points, build a livable, transparent, convenient and comfortable community life circle, and put public facilities such as life services, culture and entertainment, transportation, medical and health into reasonable arrangement. It includes kitchen/toilet anti-skid floor tile (U11), emergency call
(U12), road flatness (U13), night lighting (U14), public security (U15), surrounding traffic safety (U16), water and gas safety (U17), and community police room $\left(\mathrm{U}_{18}\right)$.

\section{Community Health $\left(\mathrm{U}_{2 \mathrm{i}}\right)$}

Community health refers to the ability to provide health information consultation and community health services for the elderly. It takes health as the center and integrates prevention, medical treatment, health care and rehabilitation as service contents. It includes the situation of community health $\left(U_{21}\right)$, outdoor fitness equipment $\left(U_{22}\right)$, community health service center (station) $\left(U_{23}\right)$, the number of surrounding hospitals $\left(\mathrm{U}_{24}\right)$, the number of surrounding pharmacies $\left(\mathrm{U}_{25}\right)$, and the community health care service $\left(\mathrm{U}_{26}\right)$.

\section{Community Comfort $\left(\mathrm{U}_{3 \mathrm{i}}\right)$}

Community comfort refers to the state of pleasure or satisfaction that the community environment gives people. Community comfort aims to integrate the community's existing resources, strengthen the community function in the natural environment, housing and public space, and promote the coordination of the community environment and the healthy life development of the elderly. It includes indoor ventilation, and sunshine $\left(U_{31}\right)$, greening $\left(U_{32}\right)$, quiet environment $\left(U_{33}\right)$, number of parks/squares $\left(U_{34}\right)$, number of public toilets $\left(\mathrm{U}_{35}\right)$, number of community home care service (Center) stations $\left(\mathrm{U}_{36}\right)$, and housekeeping service center $\left(\mathrm{U}_{37}\right)$.

\section{Community Convenience $\left(\mathrm{U}_{4 \mathrm{i}}\right)$}

Community convenience refers to the convenience degree of community life circle that meets the needs of the elderly. It includes public transportation facilities $\left(\mathrm{U}_{41}\right)$, distance between community and surrounding park/square $\left(\mathrm{U}_{42}\right)$, the distance between the community and surrounding hospitals $\left(\mathrm{U}_{43}\right)$, distance between community and community health service (Center) station $\left(\mathrm{U}_{44}\right)$, number of supermarkets and vegetable markets $\left(\mathrm{U}_{45}\right)$, and community canteen $\left(\mathrm{U}_{46}\right)$.

\section{Community Service $\left(U_{5 i}\right)$}

Community service refers to the convenience service that provides a variety of hardware facilities and software services, such as leisure and entertainment, mutual assistance services to meet the daily life and spiritual needs of the elderly. For example, property, emergency relief, housekeeping, catering, leisure and entertainment services, etc. are all 
belong to the category of community service. It consists of the service quality of property company $\left(\mathrm{U}_{51}\right)$, catering service of community and surrounding areas $\left(\mathrm{U}_{52}\right)$, household service $\left(\mathrm{U}_{53}\right)$, leisure and entertainment service $\left(\mathrm{U}_{54}\right)$, dispute mediation service $\left(U_{55}\right)$, emergency rescue service $\left(\mathrm{U}_{56}\right)$, and mutual pension service $\left(\mathrm{U}_{57}\right)$.

\section{Determining the Weight of Each Index Based on AHP}

To quarantine the scientific rationality of the index mentioned above system of age-friendly community, we used the index evaluation method to accurately reflect the elderly livable community's construction level, so it is necessary to give weight to each index. This article uses the Likert 5-point scale to measure the satisfaction of the elderly in the survey, which is divided into dissatisfied, less dissatisfied, general, more satisfied, and satisfied. They are coded as 1 point, 2 points, and 3 points respectively, 4 points, 5 points, respectively. Firstly, the original data obtained from the elderly satisfaction questionnaire are processed and the abnormal data are eliminated; then the AHP is used to calculate and determine the weight of each evaluation index, to reduce the subjectivity of index weight determination. The analytic hierarchy process (AHP) uses the judgment matrix pairwise comparison and improves accuracy; the relative scale is used to overcome the difficulty of comparing the various elements of different properties.

Let $W=\left(w_{1}, w_{2}, \ldots, w_{n}\right), w_{1}+w_{2}+\ldots+w_{n}=1$, the vector $W$ is the sorting vector of the relative importance of each element. Let $a_{i j}=w_{i} / w_{j}$, which means to start from the evaluation index $i$, compare the importance of the $i$-th index relative to the $j$-th index, and construct the following judgment matrix A, whose element value AIJ reflects people's understanding of the relative importance of each element a. ${ }^{21}$

$$
\begin{aligned}
A & =\left[\begin{array}{cccc}
a_{11} & a_{12} & \cdots & a_{1 n} \\
a_{21} & a_{22} & \cdots & a_{2 n} \\
\vdots & \vdots & \cdots & \vdots \\
a_{n 1} & a_{n 2} & \cdots & a_{n n}
\end{array}\right] \\
& =\left[\begin{array}{cccc}
w_{1} / w_{1} & w_{1} / w_{2} & \cdots & w_{1} / w_{n} \\
w_{2} / w_{1} & w_{2} / w_{2} & \cdots & w_{2} / w_{n} \\
\vdots & \vdots & \cdots & \vdots \\
w_{n} / w_{1} & w_{n} / w_{2} & \cdots & w_{n} / w_{n}
\end{array}\right]
\end{aligned}
$$

It can be seen from the above formula

$$
\begin{aligned}
A w & =\left[\begin{array}{cccc}
w_{1} / w_{1} & w_{1} / w_{2} & \cdots & w_{1} / w_{n} \\
w_{2} / w_{1} & w_{2} / w_{2} & \cdots & w_{2} / w_{n} \\
\vdots & \vdots & \cdots & \vdots \\
w_{n} / w_{1} & w_{n} / w_{2} & \cdots & w_{n} / w_{n}
\end{array}\right]\left[\begin{array}{c}
w_{1} \\
w_{2} \\
\vdots \\
w_{n}
\end{array}\right] \\
& =n\left[\begin{array}{c}
w_{1} \\
w_{2} \\
\vdots \\
w_{n}
\end{array}\right]
\end{aligned}
$$

So there are $A w=n w,(A-n I) w=0$. Where I is the identity matrix.

Let $\lambda_{\max }$ be the largest eigenvalue of the matrix $A$. Its corresponding feature vector (normalization) is the weight vector $w$, that is, $A w=\lambda_{\max } w$, to find out $w$ and determine the weight of each evaluation index. ${ }^{22}$

\section{Fuzzy Comprehensive Evaluation Model of an Age-Friendly Community Establishment of the Evaluation Result Set}

The evaluation of the model was divided into five levels, and the evaluation set $V=\left\{V_{1}, V_{2}, V_{3}, V_{4}, V_{5}\right\}$, which was shown in Table 1.

\section{Determination of the Evaluation Factor Set and Evaluation Factor Set of the Evaluation Elements}

(1)Evaluation factor set: $U=\left\{U_{1}, U_{2}, U_{3}, U_{4}, U_{5}\right\}$

(2)Evaluation factor set of the evaluation elements:

$U_{1 \mathrm{i}}=\left\{U_{11}, U_{12}, U_{13}, U_{14}, U_{15}, U_{16}, U_{17}, U_{18}\right\}$;

$U_{2 \mathrm{i}}=\left\{U_{21}, U_{22}, U_{23}, U_{24}, U_{25}, U_{26}\right\}$;

$U_{3 \mathrm{i}}=\left\{U_{31}, U_{32}, U_{33}, U_{34}, U_{35}, U_{36}, U_{37}\right\}$;

$U_{4 \mathrm{i}}=\left\{U_{41}, U_{42}, U_{43}, U_{44}, U_{45}, U_{46}\right\}$;

$U_{5 \mathrm{i}}=\left\{U_{51}, U_{52}, U_{53}, U_{54}, U_{55}, U_{56}, U_{57}\right\}$

\section{Construction of Fuzzy Relation Matrix}

The fuzzy relation matrix represents the fuzzy relationship between the evaluation index and the evaluation grade,

$$
R i j=\left[\begin{array}{cccc}
r_{11} & r_{12} & \cdots & r_{1 n} \\
r_{21} & r_{22} & \cdots & r_{2 n} \\
\vdots & \vdots & \cdots & \vdots \\
r_{n 1} & r_{n 2} & \cdots & r_{n n}
\end{array}\right]
$$

Table I Evaluation Standard of Elderly Livable Communities

\begin{tabular}{|l|l|l|l|l|}
\hline Excellent & Good & Average & Fair & Poor \\
\hline$V_{1}$ & $V_{2}$ & $V_{3}$ & $V_{4}$ & $V_{5}$ \\
$8 \sim 10$ & $6 \sim 8$ & $4 \sim 6$ & $2 \sim 4$ & $0 \sim 2$ \\
\hline
\end{tabular}


The comprehensive membership degree is obtained,

$$
B=\left(b_{1}, b_{2}, \ldots, b_{n}\right)=W^{T} \cdot R_{i j}
$$

Where,

$$
b_{j}=\sum_{i=1}^{n} w_{i j} r_{i j}
$$

\section{Grade Determination of Maximum Membership Principle}

The comprehensive membership degree is normalized, and the evaluation grade of each index is calculated according to the established evaluation grade value.

$$
\begin{gathered}
b_{j}^{\prime}=\frac{b_{j}}{\sum_{j=1}^{m} b_{j}}, \\
p_{j}=\sum_{i=1}^{m} b_{j}^{\prime} V_{j}
\end{gathered}
$$

The final evaluation results correspond to the intervals in the evaluation rating table, to determine the satisfaction degree of the elderly community.

\section{Case Study on the Fuzzy Comprehensive Evaluation of the Age-Friendly Community in Hefei}

In order to ensure the comprehensiveness of the evaluation, this paper selected the urban communities in five major urban areas of Hefei in China as the evaluation objects, including Bao-he District, Lu-yang District, Bin-hu District, Shu-shan District and High-tech Zone. In 2016, the Development and Reform Commission incorporated Hefei into the Yangtze River Delta Urban Agglomeration development plan. In 2018, among the performance appraisal results of the second batch of pilot areas supported by the central government for the reform of home-based and communitybased elderly care services, eight of the 28 pilot cities nationwide were rated as excellent, and Hefei ranked the fourth. ${ }^{23}$

$$
A=\left[\begin{array}{cccc}
1 & w_{1} / w_{2} & w_{1} / w_{3} & w_{1} / w_{4} \\
w_{2} / w_{1} & 1 & w_{2} / w_{3} & w_{2} / w_{4} \\
w_{3} / w_{1} & w_{3} / w_{2} & 1 & w_{3} / w_{4} \\
w_{4} / w_{1} & w_{4} / w_{2} & w_{4} / w_{3} & 1 \\
w_{5} / w_{1} & w_{5} / w_{2} & w_{5} / w_{3} & w_{5} / w_{4} \\
w_{6} / w_{1} & w_{6} / w_{2} & w_{6} / w_{3} & w_{6} / w_{4} \\
w_{7} / w_{1} & w_{7} / w_{2} & w_{7} / w_{3} & w_{7} / w_{4} \\
w_{8} / w_{1} & w_{8} / w_{2} & w_{8} / w_{3} & w_{8} / w_{4}
\end{array}\right.
$$

In terms of the total economic volume, the GDP of Hefei in 2019 is 940.94 billion yuan, which is a city with strong innovation vitality and high-quality economic development in Anhui Province. From the perspective of population structure, the total population of Hefei in 2019 is 8.189 million, of which the elderly population (over 60 years old) is $1,355,300$, accounting for $16.55 \%$ of the total population. The sample City Hefei selected in this paper has a firm representative.

This paper contacted scholars, community secretaries, heads of social organizations (in the field of service for the elderly) and staff of several government civil affairs departments in Colleges and universities at home and abroad to score the weight of each index. A total of 1426 valid questionnaires were collected from the old and new communities who were over 60 years old and had lived in the community for more than six months. The questionnaire survey obtained the satisfaction degree and original data of the elderly to the community indicators. Then counted the frequency of each index's specific score (the score value is 5-point system), take the frequencies as the weight to calculate the weighted average score of each index and normalize it to obtain the comprehensive score of each index after adjustment, and then construct the judgment matrix to obtain the comprehensive weight vector of each index from the maximum eigenvalue.

\section{Determination of Index Weight}

Taking the eight two-level indicators of the community security factor as an example, the weight determination process is shown in Table 2.

The judgement matrix can be drawn from Table 2 .

$\left.\begin{array}{cccc}w_{1} / w_{5} & w_{1} / w_{6} & w_{1} / w_{7} & w_{1} / w_{8} \\ w_{2} / w_{5} & w_{2} / w_{6} & w_{2} / w_{7} & w_{2} / w_{8} \\ w_{3} / w_{5} & w_{3} / w_{6} & w_{3} / w_{7} & w_{3} / w_{8} \\ w_{4} / w_{5} & w_{4} / w_{6} & w_{4} / w_{7} & w_{4} / w_{8} \\ 1 & w_{5} / w_{6} & w_{5} / w_{7} & w_{5} / w_{8} \\ w_{6} / w_{5} & 1 & w_{6} / w_{7} & w_{6} / w_{8} \\ w_{7} / w_{5} & w_{7} / w_{6} & 1 & w_{7} / w_{8} \\ w_{8} / w_{5} & w_{8} / w_{6} & w_{8} / w_{7} & 1\end{array}\right]$,




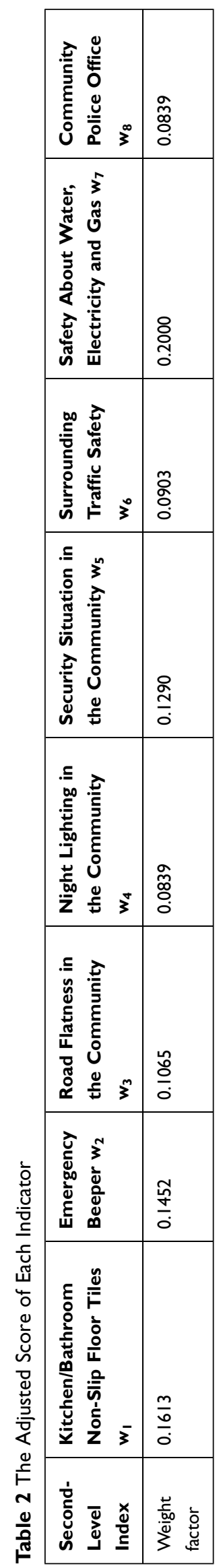

The maximum eigenvalue of matrix $\mathrm{A}$ is 8 ,

The corresponding eigenvector is normalized to $\left(\begin{array}{c}0.1613 \\ 0.1452 \\ 0.1065 \\ 0.0839 \\ 0.129 \\ 0.0903 \\ 0.2 \\ 0.0839\end{array}\right)$, the weight of anti-skid floor tile of kitchen/ toilet is 0.1613 , the weight of emergency pager is 0.1452 , the weight of Road flat condition is 0.1065 , the weight of nighttime lighting is 0.0839 , the weight of community security is 0.129 , the weight of surrounding traffic safety is 0.0903 , the weight of water, electricity and gas safety is 0.2 The weight of the community police room is 0.0839 . Using a similar method, we can get the weight of other secondary indicators relative to the first level indicators, and each level of indicators relative to the urban elderly livable community.

\section{Evaluation of Age-Friendly Community in Hefei}

Combined with the weight data, evaluation data and evaluation grade of 20 experts, the Hefei elderly livable community index evaluation are summarized in Table 3 (for simplified calculation, the weight is taken to three decimal places).

According to Table 3, the fuzzy comprehensive evaluation method is used to evaluate the factors.

\section{Evaluation of Community Safety Function $W_{1}=[0.1613,0.1452,0.1065,0.0839,0.129,0.0903,0.2$, 0.0839]}

$$
R_{1}=\left[\begin{array}{c}
0.26040 .43280 .19360 .08540 .0276 \\
0.24520 .41520 .21460 .0910 .0334 \\
0.2970 .4460 .1560 .0770 .024 \\
0.2460 .4120 .1940 .1130 .035 \\
0.2450 .4370 .1880 .090 .04 \\
0.2540 .4170 .2080 .0940 .026 \\
0.260 .4520 .2220 .0530 .013 \\
0.2210 .3580 .2620 .1050 .053
\end{array}\right]
$$

Membership vector $B_{1}=W_{1} R_{1}=[0.2549,0.4266$, $0.2047,0.084,0.029]$, and the $B_{1}{ }^{\prime}$ can be obtained after normalization, $B_{1}{ }^{\prime}=[0.255,0.4267,0.2048,0.1744,0.0842$, 0.0294], $\mathrm{P}_{1}=\sum_{\mathrm{j}=1}^{\mathrm{m}} \mathrm{bj}^{\prime} \mathrm{Vj}=6.5879$,

$$
\mathrm{P}_{1} \in[6,8] \text {, }
$$


Table 3 Summary of Index Evaluation Results of Elderly Livable Communities in Hefei

\begin{tabular}{|c|c|c|c|c|c|c|c|c|}
\hline \multirow[t]{2}{*}{ First-Level Index } & \multirow{2}{*}{$\begin{array}{l}\text { Weight } \\
\text { Factor }\end{array}$} & \multirow[t]{2}{*}{ Second-Level Index } & \multirow{2}{*}{$\begin{array}{l}\text { Weight } \\
\text { Factor }\end{array}$} & \multicolumn{5}{|c|}{ Evaluation Results } \\
\hline & & & & Excellent & Good & Average & Poor & Terrible \\
\hline \multirow{8}{*}{$\begin{array}{l}\text { Community safety } \\
\text { factor }\end{array}$} & \multirow[t]{8}{*}{0.2513} & Kitchen/bathroom non-slip floor tiles & 0.1613 & 0.2604 & 0.4328 & 0.1936 & 0.0854 & 0.0276 \\
\hline & & Emergency beeper & 0.1452 & 0.2452 & 0.4152 & 0.2148 & 0.091 & 0.0334 \\
\hline & & Road flatness in the community & 0.1065 & 0.297 & 0.446 & 0.156 & 0.077 & 0.024 \\
\hline & & Night lighting in the community & 0.0839 & 0.246 & 0.412 & 0.194 & 0.113 & 0.035 \\
\hline & & Security situation in the community & 0.129 & 0.245 & 0.437 & 0.188 & 0.09 & 0.04 \\
\hline & & Surrounding Traffic Safety & 0.0903 & 0.254 & 0.417 & 0.208 & 0.094 & 0.026 \\
\hline & & Safety about water, electricity and gas & 0.2 & 0.26 & 0.452 & 0.222 & 0.053 & 0.013 \\
\hline & & Community Police Office & 0.0839 & 0.221 & 0.358 & 0.262 & 0.105 & 0.053 \\
\hline \multirow{6}{*}{$\begin{array}{l}\text { Community health } \\
\text { factors }\end{array}$} & \multirow[t]{6}{*}{0.1861} & Community health & 0.1133 & 0.26 & 0.39 & 0.185 & 0.125 & 0.04 \\
\hline & & $\begin{array}{l}\text { Outdoor fitness equipment and usage } \\
\text { status }\end{array}$ & 0.1567 & 0.205 & 0.359 & 0.274 & 0.112 & 0.049 \\
\hline & & Community Health Center & 0.23 & 0.204 & 0.373 & 0.305 & 0.091 & 0.025 \\
\hline & & Number of surrounding hospitals & 0.17 & 0.221 & 0.378 & 0.292 & 0.085 & 0.024 \\
\hline & & Number of nearby pharmacies & 0.1433 & 0.249 & 0.409 & 0.266 & 0.066 & 0.0097 \\
\hline & & Community health care services & 0.1867 & 0.215 & 0.399 & 0.27 & 0.087 & 0.027 \\
\hline \multirow{7}{*}{$\begin{array}{l}\text { Community comfort } \\
\text { factor }\end{array}$} & \multirow[t]{7}{*}{0.1611} & Indoor ventilation, sunshine & 0.1567 & 0.2188 & 0.3836 & 0.2814 & 0.0882 & 0.02694 \\
\hline & & Community greening & 0.1167 & 0.403 & 0.377 & 0.128 & 0.067 & 0.023 \\
\hline & & $\begin{array}{l}\text { The quietness of the community } \\
\text { environment }\end{array}$ & 0.1233 & 0.37 & 0.398 & 0.122 & 0.079 & 0.031 \\
\hline & & $\begin{array}{l}\text { Number of community and surrounding } \\
\text { parks/squares }\end{array}$ & 0.1867 & 0.228 & 0.397 & 0.248 & 0.09 & 0.027 \\
\hline & & $\begin{array}{l}\text { Number of public toilets surrounding } \\
\text { the community }\end{array}$ & 0.0967 & 0.171 & 0.31 & 0.289 & 0.151 & 0.078 \\
\hline & & $\begin{array}{l}\text { Number of community home care } \\
\text { service centers }\end{array}$ & 0.1833 & 0.196 & 0.346 & 0.293 & 0.123 & 0.042 \\
\hline & & Household management service Center & 0.1367 & 0.173 & 0.338 & 0.325 & 0.13 & 0.033 \\
\hline \multirow{6}{*}{$\begin{array}{l}\text { Community } \\
\text { convenience factors }\end{array}$} & \multirow[t]{6}{*}{0.1807} & Public transportation(bus, subway) & 0.18 & 0.247 & 0.413 & 0.21 & 0.102 & 0.028 \\
\hline & & $\begin{array}{l}\text { Distance between community and } \\
\text { surrounding park }\end{array}$ & 0.1 & 0.241 & 0.367 & 0.253 & 0.109 & 0.03 \\
\hline & & $\begin{array}{l}\text { Distance between community and } \\
\text { surrounding hospital }\end{array}$ & 0.1667 & $0.24 I$ & 0.372 & 0.282 & 0.083 & 0.021 \\
\hline & & Distance from health service center & 0.1867 & 0.208 & 0.37 & 0.298 & 0.097 & 0.027 \\
\hline & & $\begin{array}{l}\text { Number of supermarkets and vegetable } \\
\text { markets }\end{array}$ & 0.2 & 0.28 & 0.431 & 0.22 & 0.064 & 0.0055 \\
\hline & & Community canteen & 0.1667 & 0.165 & 0.279 & 0.307 & 0.168 & 0.082 \\
\hline
\end{tabular}

(Continued) 
Table 3 (Continued).

\begin{tabular}{|c|c|c|c|c|c|c|c|c|}
\hline \multirow[t]{2}{*}{ First-Level Index } & \multirow{2}{*}{$\begin{array}{l}\text { Weight } \\
\text { Factor }\end{array}$} & \multirow[t]{2}{*}{ Second-Level Index } & \multirow{2}{*}{$\begin{array}{l}\text { Weight } \\
\text { Factor }\end{array}$} & \multicolumn{5}{|c|}{ Evaluation Results } \\
\hline & & & & Excellent & Good & Average & Poor & Terrible \\
\hline \multirow[t]{7}{*}{$\begin{array}{l}\text { Community service } \\
\text { factor }\end{array}$} & \multirow[t]{7}{*}{0.2209} & $\begin{array}{l}\text { The quality of property company } \\
\text { service }\end{array}$ & 0.1533 & 0.225 & 0.39 & 0.238 & 0.097 & 0.05 \\
\hline & & $\begin{array}{l}\text { Community and surrounding catering } \\
\text { services }\end{array}$ & 0.1467 & 0.207 & 0.417 & 0.274 & 0.092 & 0.0097 \\
\hline & & Household management service & 0.14 & 0.176 & 0.323 & 0.3 & 0.118 & 0.034 \\
\hline & & Leisure and entertainment services & 0.1233 & 0.196 & 0.387 & 0.264 & 0.119 & 0.034 \\
\hline & & Dispute Mediation Service & 0.1 & 0.202 & 0.314 & 0.335 & 0.11 & 0.038 \\
\hline & & Emergency rescue service & 0.16 & 0.177 & 0.33 & 0.347 & 0.114 & 0.033 \\
\hline & & Mutual Aid Service & 0.1767 & 0.23 & 0.336 & 0.292 & 0.107 & 0.033 \\
\hline
\end{tabular}

From the score, we can see that the community security function is the best, which is relatively high at this level. Generally speaking, the community safety function of Hefei community construction is relatively complete.

\section{Community Health Function Improvement $W_{2}=[0.1133,0.1567,0.23,0.17,0.1433,0.1867]$}

Membership vector $B_{2}=W_{2} R_{2}=[0.0934,0.1264$, $0.4355,0.2298,0.115]$, and the $B_{2}{ }^{\prime}$ can be obtained after normalization,

$B_{2}^{\prime}=\left[\begin{array}{lll}0.2221, & 0.384,0.2725,0.0929,0.0285\end{array}\right], \mathrm{P}_{2}=$ $\sum_{\mathrm{j}=1}^{\mathrm{m}} \mathrm{bj}^{\prime} \mathrm{Vj}=6.3566$,

$\mathrm{P}_{2} \in[6,8]$,

Therefore, the community health performance is good. The community health function is relatively perfect, which can meet the elderly's needs of health facilities and services provided by the community.

\section{Community Comfort Factors}

$W_{3}=[0.1567,0.1167,0.1233,0.1867,0.0967,0.1833,0.14]$

Membership vector $B_{3}=W_{3} R_{3}=[0.2456,0.3669$, $0.2465,0.1031,0.0355]$, and the $B_{3}{ }^{\prime}$ can be obtained after normalization,

$B_{3}^{\prime}=[0.2462,0.3678,0.2471,0.1034,0.0356], \quad \mathrm{P}_{3}=$ $\sum_{\mathrm{j}=1}^{\mathrm{m}} \mathrm{bj}^{\prime} \mathrm{Vj}=6.3717$,

$\mathrm{P}_{3} \in[6,8]$,

Therefore, the community comfort factors are pretty good, and community comfort plays a more positive role in constructing a livable community in the whole city.

\section{Community Convenience Factors}

$W_{4}=[0.18,0.1,0.1667,0.1867,0.2,0.1667]$

Membership vector $B_{4}=W_{4} R_{4}=[0.231,0.3748$, $0.261,0.102,0.0314]$, and the $B_{4}{ }^{\prime}$ can be obtained after normalization,

$$
B_{4}{ }^{\prime}=[0.231,0.3748,0.2609,0.102,0.0313], \mathrm{P}_{4}=\sum_{\mathrm{j}=1}^{\mathrm{m}} \mathrm{bj}^{\prime} \mathrm{Vj}
$$
$=6.3444$,

$\mathrm{P}_{4} \in[6,8]$,

The community convenience factor is pretty good, which can meet the elderly's travel and lifestyle convenience needs.

\section{Community Service Factors}

$W_{5}=[0.1533,0.1467,0.14,0.1233,0.1,0.16,0.18]$

Membership vector $B_{5}=W_{5} R_{5}=[0.2028,0.3575$, $0.292,0.1077,0.033]$, and the $B_{5}{ }^{\prime}$ can be obtained after normalization,

$$
\begin{aligned}
& B_{5}{ }^{\prime}=[0.2043,0.3601,0.294,0.1085,0.0332], \mathrm{P}_{5}=\sum_{\mathrm{j}=1}^{\mathrm{m}} \mathrm{bj}^{\prime} \mathrm{Vj} \\
& 6.1881, \\
& \mathrm{P}_{5} \in[6,8],
\end{aligned}
$$$$
=6.1881 \text {, }
$$

The performance of community service factors are fair, but the score at this level is relatively low. Consequently, it is necessary to strengthen the role of community service in the construction of livable communities.

\section{The Overall Evaluation on Age-Friendly Community}

$\mathrm{W}$ and $\mathrm{R}$ are the fuzzy relations among ranking vector, evaluation index and evaluation grade. 


$$
\begin{aligned}
R & =\left[B_{1}, B_{2}, B_{3}, B_{4}, B_{5}\right]^{T} \\
& =\left[\begin{array}{lllll}
0.255 & 0.4266 & 0.2047 & 0.0842 & 0.0293 \\
0.222 & 0.3836 & 0.2722 & 0.0928 & 0.0285 \\
0.246 & 0.3669 & 0.2465 & 0.1031 & 0.0355 \\
0.231 & 0.3748 & 0.2609 & 0.1020 & 0.0314 \\
0.203 & 0.3575 & 0.2919 & 0.1077 & 0.0329
\end{array}\right]
\end{aligned}
$$

Membership vector $B=\left[b_{1}, b_{2}, \ldots, b n\right]=W R=$ $[0.1867,0.384,0.253,0.097,0.0313]$, and the $B^{\prime}$ can be obtained after normalization,

$B^{\prime}=[0.1959,0.4033,0.2659,0.102,0.0329], \mathrm{P}=\sum_{\mathrm{j}=1}^{\mathrm{m}} \mathrm{bj}^{\prime} \mathrm{Vj}$ $=6.2546$,

$\mathrm{P} \in[6,8]$,

Therefore, the overall level of age-friendly community in Hefei is good.

In this paper, the scores of various indicators and the the evaluation of various indicators are obtained through fuzzy analysis and evaluation of various indicators. In the analysis process of this article, the basic principles and analytical interpretation methods of the fuzzy evaluation method are followed.

\section{Discussion}

Taking the urban community of Hefei as an example, combined with the needs and satisfaction of the elderly, this paper comprehensively evaluated the livable elderly community from five aspects: community safety, community health, community comfort, community convenience, and community service factors. The AHP analytic hierarchy process was used to determine the index weight, and the fuzzy comprehensive evaluation model was used for comprehensive and systematic quantitative evaluation. Compared with other qualitative methods, it has the advantages of scientificity, applicability and feasibility, which has a specific guiding role in improving the construction of livable communities for the elderly in cities.

Based on the above analysis, it can be seen that the overall level of Hefei community is relatively high. Among them, the community safety score is the highest, the community service score is the low. The survey data shows that the elderly have the highest overall satisfaction with community safety, with more than $70 \%$ of people saying that home safety such as kitchen/toilet anti-skid facilities are more satisfied; more than $74.3 \%$ of people saying that travel safety is more satisfied, such as flat roads. More than $67 \%$ of people said they were satisfied with the safety of the surrounding traffic. In terms of community comfort, the overall satisfaction of the elderly is relatively high. More than $78 \%$ of people said that the greening of the community was relatively satisfactory; more than $76.8 \%$ said that the quietness of the community was relatively satisfactory; more than $62.5 \%$ said that the number of parks/squares around the community was quite satisfactory. In terms of community health, more than $65 \%$ of people said they were satisfied with the health situation in the community; more than $56.4 \%$ said they were satisfied with the fitness equipment and the usage; more than $61.4 \%$ said they were more satisfied with the community medical and health service. In terms of community convenience, $66 \%$ of people said they were satisfied with public transport facilities; $60.8 \%$ said they were satisfied with the distance between the community and the surrounding parks/squares; $57.8 \%$ said the distance between the community and the community health service (Center) was quite satisfactory. However, in terms of community service, the overall score is the lowest. The overall satisfaction of the elderly is not high, and the proportion of people expressing satisfaction is only close to $50 \%$, which is relatively lower compared to other indicators.

At the same time, we found that the overall evaluation and the first-class indicators of livable community care in Hefei were maintained at a reasonable level. Through the calculation of various indicators, we found that the number of community health service stations, the number of community canteens, the number of community home-based elderly care service (Center) stations, the number of community canteens, community home-based elderly care service (Center) stations, and the number of community health service stations, community canteens, community home the satisfaction of emergency rescue service, the distance between community and community health service (Center) and mutual care service was relatively lower, and the level of satisfaction is not high. Consequently, it is necessary to strengthen further the transformation and improvement of the existing facilities in the community in the above aspects.

According to the above research conclusions, the overall score of community service in the construction of the elderly community is low. Improving the quality of service has become the key to improving the satisfaction of the elderly in the community. Considering the uniqueness of the elderly community and the individual needs of the elderly, the quality of service of the elderly community cannot be improved from a single aspect. It is necessary to form specific measures with operational effects, including improving infrastructure, upgrading medical and health resources, optimizing the community living environment, 
and improving the elderly care service system. Therefore, this article puts forward the following suggestions.

First of all, we should improve infrastructure to facilitate the living environment of the elderly. It is necessary to improve the level of home safety, strengthen the aging suitable transformation of corridors, toilets and living rooms for the elderly, as well as safety auxiliary facilities such as home fillet treatment, emergency pager and installation of handrails, to provide the elderly with the transformation and improvement of family facilities suitable for aging. In addition, it is necessary to continuously improve the level of community and traffic safety, strengthen the construction of barrier-free facilities for installing of public aisle handrails and the anti-skid function of ramps, curves, steps, etc. It is equipped with fire fighting and emergency rescue equipment to check the insecurity caused by the old buildings and aging circuit facilities. We should investigate all kinds of potential traffic safety and public security risks, give full play to the role of volunteers, build a new model of police-civilian cooperation, and enhance the sense of security and belonging of the elderly in the community.

Secondly, improve the supply of medical resources and make it easier for the elderly to seek medical treatment. To build a combination of medical and nursing modes, health services will be extended to the elderly family. Based on the Internet plus home care information system, the information collection and data analysis platform for the elderly are established for the elderly's living conditions and tracking and monitoring of chronic diseases. We will strengthen health management and emergency relief services for the elderly. Community integration service resources for the elderly, encourage volunteers, social organizations and other social forces to participate in the integrated medical and nursing services, expand medical service resources such as health service centers, identify needs, and provide targeted services such as health consultation, disease diagnosis, treatment and nursing, rehabilitation and health care for the elderly.

Thirdly, it is necessary to add convenient service points, build livable, clear, convenient and comfortable community life circle, and put public facilities such as life services, culture and entertainment, transportation, medical and health into reasonable arrangement. In particular, parks, squares and other places improve the convenience and accessibility of elderly life. We should adopt the methods of purchase, replacement and lease to open up the community old-age service room, complete all kinds of elderly service facilities, and gradually complete the transformation of urban old community service facilities suitable for aging. In addition, we should strengthen the convenience function of public transport, elderly care service center (station), community canteen, cultural activity center, surrounding park, community service center and community medical service institutions and other public service facilities. At the same time, we should fully consider the needs of the elderly, make the public service facilities suitable for the physiological and psychological characteristics of the elderly of all ages, and improve the livable quality of the elderly.

Last but not least, it is necessary to strengthen the investigation on the service demand and actual satisfaction of the elderly in the community, and explore their diversified service needs. Relying on the information platform of socialized elderly care service, we should optimize and integrate the elderly care service resources in the whole city, expand the community coverage of resources, strengthen the extension of elderly care services to the community, and provide services such as meal delivery, meal assistance, bath assistance, medical assistance, and door-to-door care for the elderly in the community. Taking Internet plus as technological support, we should gradually promote the construction of suitable aging and intelligent livable communities, provide more convenient integrated services for the elderly at home to cover emergency assistance, health care, shopping and leisure, and telemedicine, and meet the material, social, cultural and psychological needs of the elderly, and build a livable virtual elderly community.

\section{Conclusions}

In summary, this study revealed that the overall level of Hefei community is relatively high, and the overall evaluation and the first-class indicators of livable community care in Hefei were maintained at a reasonable level. Among them, the community safety score is the highest, the community comfort is higher, followed by community health, convenience, and community service score is the lowest. Moreover, the results also found that improving the quality of service has become the key to improving the satisfaction of the elderly in the community. Furthermore, this study suggested that it is necessary to form specific measures with operational effects, including improving infrastructure, upgrading medical and health resources, optimizing the community living environment, and improving the elderly care service system. The limitation 
of this study is that the data sample is only limited to Hefei. Due to regional differences in China, future studies may consider including an evaluation of the satisfaction of elderly livable community construction in different cities.

\section{Ethical Statement}

The study received ethical approval from the Academic Ethics Committee of Party School of Anhui Provincial Committee (Anhui Academy of Governance). Informed consent was obtained from the questionnaire participants.

\section{Acknowledgment}

This paper is supported by the significant Humanities and Social Sciences project in Anhui Province "Research on community elderly care service system in Anhui characteristic cities from the perspective of shared development" (SK2019ZD63).

\section{Disclosure}

The authors report no conflicts on interest in this work.

\section{References}

1. Greenfield EA. Getting started: an empirically derived logic model for age-friendly community initiatives in the early planning phase. $J$ Gerontol Soc Work. 2018;61(3):295-312. doi:10.1080/01634372.2018.1432736

2. WHO. Global Age-Friendly Cities: A Guide. Geneva, Switzerland: World Health Organization Press; 2007.

3. Alley D, Liebig P, Pynoos J, Banerjee T, Choi IH. Creating elder-friendly communities: preparations for an aging society. J Gerontol Soc Work. 2007;49(1-2):1-18. doi:10.1300/J083v49n01_01

4. Brownson RC, Hoehner CM, Day K, Forsyth A, Sallis JF. Measuring the built environment for physical activity: state of the science. Am J Prev Med. 2009;36(4):S99-S123. doi:10.1016/j.amepre.2009.01.005

5. Lawton MP. An ecological theory of aging applied to elderly housing. $J$ Archit Educ. 1977;31(1):8-10. doi:10.1080/10464883.1977.11102585

6. Menec VH, Means R, Keating N, Parkhurst G, Eales J. Conceptualizing age-friendly communities. Can J Aging. 2011;30 (3):479-493. doi:10.1017/S0714980811000237

7. Fitzgerald KG, Caro FG. An overview of age-friendly cities and communities around the world. J Aging Soc Policy. 2014;26(12):1-18. doi:10.1080/08959420.2014.860786

8. Scharlach AE, Lehning AJ. Ageing-friendly communities and social inclusion in the United States of America. Ageing Soc. 2013;33 (1):110-136. doi:10.1017/S0144686X12000578
9. Greenfield EA, Oberlink M, Scharlach AE, Neal MB, Stafford PB. Age-friendly community initiatives: conceptual issues and key questions. Gerontologist. 2015;55(2):191-198. doi:10.1093/geront/ gnv005

10. Li S, Yang ZZ, Contents T. Index system of evaluating livable community for urban elderly. Northwest Popul J. 2012;33(02):17-26.

11. Yu YF, Hu YT. Progress of international research on health impact of the built environment of communities: literature review and reflections from a perspective of physical activities. Archit $J$. 2017;02:33-38.

12. Li X, Xu Y, Zhou D. The study and practive of livable environment for the elderly in China. Archit J. 2016;02:16-21.

13. Zhou YM The expert interpretation of the 13th five-year plan for the development of the national career for the aged and the construction of the pension system: promote the construction of a livable environment for the elderly; 2017.Available from: http://www.cncaprc.gov. $\mathrm{cn} /$. Accessed September 4, 2021.

14. Wu XL, Qu JY. The status quo, problems of China's construction of elderly livable environment and countermeasure research. Sci Res Aging. 2016;4(08):3-12.

15. Zhang F, Shi WH. The study on the livable environment for the elderly. City. 2010;11:48-50.

16. Niu JG, Zhang Y, Lin SZ, Jin GH. Comprehensive evaluation of energy-saving renovation for existing residential buildings based on cloud model. J Civil Eng Manag. 2016;33(05):64-70.

17. Zhang C, Chan Y. Study on neighborhood satisfaction of the urban elderly in Beijing: an approach from fuzzy evaluation. Hum Geogr. 2013;28(4):47-52.

18. Li Y, Deng QY. Analysis of the implementation effect of long-term care insurance policy for the elderly based on fuzzy comprehensive evaluation. Popul Econ. 2019;6:82-96.

19. Zhang XD, Hu JC, Yang Q, et al. Research on the evaluation system of renewal for old residential district based on AHM and comprehensive assessment method. Urban Dev Res. 2017;24(12):20-27.

20. Post T, Spronk J. Performance benchmarking using interactive data envelopment analysis. Eur J Oper Res. 1999;115(3):472-487. doi:10.1016/S0377-2217(98)00022-8

21. Giddens A. The Constitution of Society: Outline of the Theory of Structuration. Berkeley: University of California Press; 1984.

22. Liu Y, Fang P, Bian D, Zhang H, Wang S. Fuzzy comprehensive evaluation for the motion performance of autonomous underwater vehicles. Ocean Eng. 2014;88:568-577. doi:10.1016/j.oceaneng.20 14.03.013

23. Ministry of Civil Affairs and Ministry of Finance of the People's Republic of China. Announcement on the results of the performance appraisal of the pilot areas supported by the second round Central finance for reforming the home and community service for the aged people the second batch of central government support for the implementation of the reform of home and community elderly care services; 2018. Available from: http://www.mca.gov.cn/. Accessed September 4, 2021.
Risk Management and Healthcare Policy

\section{Publish your work in this journal}

Risk Management and Healthcare Policy is an international, peerreviewed, open access journal focusing on all aspects of public health, policy, and preventative measures to promote good health and improve morbidity and mortality in the population. The journal welcomes submitted papers covering original research, basic science, clinical \& epidemiological studies, reviews and evaluations, guidelines, expert opinion and commentary, case reports and extended reports. The manuscript management system is completely online and includes a very quick and fair peer-review system, which is all easy to use. Visit http://www.dovepress.com/testimonials.php to read real quotes from published authors. 